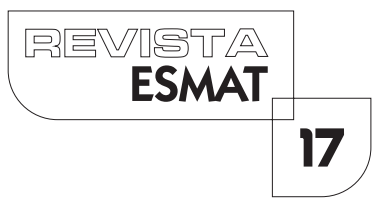

\title{
DEFESA DOS DIREITOS DAS PESSOAS COM DEFICIÊNCIA: A CONTRIBUIÇÃO DA ATUAÇÃO DO ASSISTENTE SOCIAL DA APAE DE TRÊS CORAÇÕES-MG, FUVAE E DO CONSELHO MUNICIPAL DE DIREITOS DAS PESSOAS COM DEFICIÊNCIA DE VARGINHA-MG
}

\author{
DEFENSE OF THE RIGHTS OF PERSONS WITH DISABILITIES:
}

THE CONTRIBUTION OF THE ACTION OF THE SOCIAL ASSISTANT OF APAE DE TRÊS CORAÇÕES-MG, FUVAE AND OF THE MUNICIPAL COUNCIL OF RIGHTS OF PERSONS

WITH DISABILITIES OF VARGINHA-MG

Tatiele Divino Mafra

Graduada em Serviço Social, pela Universidade Vale do Rio Verde de Três Corações. Funcionária do Conselho Municipal de Defesa dos Direitos da Pessoa com Deficiência, de Varginha-MG (CODEVA). E-mail da autora: tatielemafra@yahoo.com.br

\section{Cleusimar Cardoso Alves Almeida}

Doutoranda em Serviço Social, pela Universidade Estadual Paulista Júlio de Mesquita Filho. Mestre em Gestão Pública e Sociedade (20 |4); especialista em gestão de serviços sociais e políticas públicas (20I I); graduada em Serviço Social (20 I0). Professora da Universidade Vale do Rio Verde de Três Corações (UninCor) e assessora acadêmica da Pró-Reitoria de extensão da UninCor. E-mail: cleocardoso08@gmail.com

Adriana Giaqueto Jacinto

Docente da Graduação e Pós-Graduação em Serviço Social da Faculdade de Ciências Humanas e Sociais/Unesp. Graduada em Letras, pela Universidade de Franca (1989); graduada ( 1989), mestre (1998) e doutora (2004) em Serviço Social, pela Universidade Estadual Paulista (UNESP). E-mail: drigiaqueto@gmail.com

\section{RESUMO}

Este trabalho propõe como objetivo descrever sobre as contribuições da atuação do Assistente Social na Associação de Pais e Amigos dos Excepcionais (APAE) de Três Corações e na Fundação Varginhense de Assistência aos Excepcionais de Minas Gerais (FUVAE), de Varginha, e contribuições do trabalho do Conselho Municipal de Direitos da Pessoa com Deficiência (CODEVA), de Varginha, na viabilização e defesa dos direitos sociais das pessoas com deficiência e seus familiares. Foi realizada pesquisa de campo, com abordagem qualitativa, aplicando questionários e entrevistas semiestruturadas a 20 famílias na APAE Três Corações-MG e na FUVAE de Varginha-MG, roteiro de entrevista para 2 assistentes sociais da FUVAE e com I secretária coordenadora da APAE, e entrevistas semiestruturadas com 10 conselheiros e colaboradores do CODEVA, de Varginha. Foi possível identificar que o perfil das famílias das pessoas com deficiência assistidas pela FUVAE e APAE, são famílias de baixa renda e com acesso às informações, principalmente, devido à 
intervenção do assistente social. As contribuições deste profissional em ambas as Instituições são favoráveis para a socialização das informações e conquistas dos direitos das pessoas com deficiência. A atuação do CODEVA é importante no processo de descentralização, democratização das políticas sociais, participação comunitária e efetivação dos direitos.

PALAVRAS-CHAVE: Pessoas com Deficiência. Defesa de Direitos. Serviço Social. Conselho Municipal.

\section{ABSTRACT}

This paper aims to describe the contributions of the Social Worker in the Association of Parents and Friends of the Exceptional (APAE) of TrêsCorações and the Varginhense Foundation of Assistance to the Exceptional of Minas Gerais (FUVAE) of Varginha and contributions of the work of the Council Municipal of Rights of Persons with Disabilities (CODEVA) of Varginha in the viability and defense of the social rights of people with disabilities and their families. A field survey was carried out with a qualitative approach, applying questionnaires and semi-structured interviews to 20 families at APAE Três Corações-MG and at FUVAE in Varginha-MG, interview script for 2 social assistants from FUVAE and I coordinating secretary of APAE and, semistructured interviews with 10 counselors and employees of CODEVA de Varginha. It was possible to identify that the family profile of people with disabilities assisted by FUVAE and APAE are low income families with access to information, mainly due to the intervention of the Social Worker. The contributions of this professional in both Institutions are favorable for the socialization of information and achievement of the rights of persons with disabilities. CODEVA's actions are important in the process of decentralization, democratization of social policies, community participation and effective implementation of rights.

KEYWORDS: People with Disabilities. Defense of Rights. Social Service. City Council.

\section{INTRODUÇÃO}

A Lei Brasileira de Inclusão da Pessoa com Deficiência, no |3.|46, de 20I5, considera a pessoa com deficiência' aquela que tem impedimento de longo prazo de natureza física, mental, intelectual ou sensorial, a qual, em interação com uma ou mais barreiras, pode obstruir sua participação plena e efetiva na sociedade em igualdade de condições com as demais pessoas (BRASIL, 20I5).

I $O$ termo atualizado e utilizado neste artigo é pessoa com deficiência, institucionalizado pela Portaria $n^{\circ} 2.344$, de 2010. 
DEFESA DOS DIREITOS DAS PESSOAS COM DEFICIÊNCIA: A CONTRIBUIÇÃO DA ATUAÇÃO DO ASSISTENTE SOCIAL DA APAE DE TRÊS CORAÇÕES-MG, FUVAE E DO CONSELHO MUNICIPAL DE DIREITOS DAS PESSOAS COM DEFICIÊNCIA DE VARGINHA-MG

Esta legislação representou avanços no que se refere à garantia de direitos das pessoas com deficiência. De acordo com os dados do último Censo, de 2010, do Instituto Brasileiro de Geografia e Estatística (IBGE, 20I0), aproximadamente 45.606.048 de brasileiros possuem algum tipo de deficiência.

Acreditando nas potencialidades das pessoas com deficiência, muitas Entidades espalhadas pelo Brasil lutam pelo respeito, inclusão e direitos destas, como, por exemplo, a rede de Associações de Pais e Amigos dos Excepcionais (APAEs) e os Conselhos de Direitos das Pessoas com Deficiência. Os profissionais que atuam nessas Entidades e nesses Conselhos de Direitos tendem a viabilizar e lutar pelos direitos sociais dessas pessoas com deficiência, como os assistentes sociais e conselheiros. No contexto de atuação de assistentes sociais nas APAEs, estudos de Oliveira (20 I2) apontam que foram realizadas poucas pesquisas abordando o tema, mesmo sendo um importante campo de atuação para o Serviço Social.

Diante disso, este artigo traz como objetivo geral: Descrever sobre as contribuições da atuação do Assistente Social na APAE da cidade de Três Corações-MG e na Fundação Varginhense de Assistência aos Excepcionais (FUVAE), de Varginha-MG, e as contribuições do trabalho do Conselho Municipal de Direitos da Pessoa com Deficiência (CODEVA), de Varginha-MG, na viabilização e defesa dos direitos das Pessoas com Deficiência e de seus familiares.

Assim, a fim de contemplar os objetivos propostos, realizou-sea pesquisa de campo na APAE de Três Corações-MG, na FUVAE e no CODEVA, de Varginha-MG. A pesquisa foi realizada mediante aprovação pelo Comitê de Ética da Universidade Vale do Rio Verde de Três Corações (UninCor). A pesquisa teve abordagem qualitativa, sendo a técnica de recolha de dados realizada com a aplicação de questionário e entrevistas semiestruturadas com 20 pessoas. Os questionários possibilitaram traçar o perfil socioeconômico das famílias participantes da pesquisa e frequentes na APAE e FUVAE. Por meio das entrevistas semiestruturadas com as 20 famílias, foi possível verificar a visão dos pais em relação à atuação do assistente social na APAE de Três Corações e na FUVAE, de Varginha, mediante a viabilização e defesa de direitos sociais das pessoas com deficiência e no conhecimento dos pais e/ou responsáveis sobre legislações.

Também se utilizou de um roteiro de entrevista aplicado com duas assistente sociais da FUVAE e uma secretária coordenadora da APAE, buscando verificar a opinião dessas profissionais a respeito de suas contribuições na defesa e viabilização dos direitos sociais na vida das pessoas com deficiência e familiares assistidos pelas referidas Instituiçõos.

Realizaram-se, ainda, entrevistas semiestruturadas com 10 conselheiros e colaboradores integrantes do CODEVA, de Varginha-MG, a fim de verificar o impacto da atuação desse Conselho diante de viabilização e acesso aos direitos das pessoas com deficiência.

A seleção da amostra foi feita pelo critério da intencionalidade, e foram entrevistados os pais e/ou responsáveis que comparecem frequentemente na Instituição e 
possuem seus filhos assistidos pela APAE de Três Corações e FUVAE, de Varginha, sempre presentes nas oficinas, projetos, atendimentos clínicos e escola de pais. No caso do CODEVA também foram entrevistados os conselheiros e colaboradores mais atuantes e assíduos nas atividades do Conselho.

As entrevistas foram gravadas mediante autorização, ressaltando que as informações prestadas ficaram sob sigilo, a fim de preservar a identidade dos participantes da pesquisa.

Os dados foram analisados mediante categorias e subcategorias de análises, como: Perfil das Famílias, Impactos Sociais (pessoa com deficiência perante a sociedade) e Econômicos (renda, concessão de benefícios, acesso a direitos sociais) na vida das famílias atendidas pela APAE e pela FUVAE; Atuação do assistente social na APAE e FUVAE; Atuação do Conselho Municipal de Defesa dos Direitos da Pessoa com Deficiência, de Varginha-MG, na vida dos usuários. As entrevistas foram transcritas, e realizadas análises e inferências dos dados.

Posto isso, a seguir são descritas informações sobre o surgimento das APAEs no Brasil; sobre a APAE de Três Corações e FUVAE, de Varginha. Mencionada na seção seguinte a atuação dos assistentes sociais e do Conselho Municipal dos Direitos das Pessoas com Deficiência. Posteriormente são descritas as considerações finais do estudo.

\section{O SURGIMENTO DAS APAES NO BRASIL}

Impulsionados pela Declaração dos Direitos Humanos, foram surgindo mobilizações sociais e estas foram se espalhando e ampliando por todo o território brasileiro, constituindo uma rede de promoção e defesa dos direitos das pessoas com deficiência intelectual e múltipla, conhecida popularmente como Movimento Apaeano.

Marques (20l I) ressalta que o Movimento Apaeano se espalhou por várias cidades e estados diferentes, sendo considerado o maior movimento social e comunitário do mundo na sua área de atuação. "Surgindo famílias empenhadas em buscar soluções alternativas para que seus filhos com deficiência intelectual ou múltipla alcancem condições de serem incluídos na sociedade" (FEDERAÇÃO NACIONAL DAS APAES, 2017, p. I).

A primeira instituição brasileira especializada no atendimento a pessoas com deficiência foi em 1926, tendo sido fundado o Instituto Pestalozzi, em Canoas/RS. Em 1932, foi instituída uma sede em Belo Horizonte/MG, e, em 1948, uma em Niterói/ RJ (LANNA JÚNIOR, 2010).

Em 1954, Souza (2016) aponta que houve a primeira iniciativa de reunir pais e amigos das pessoas com deficiência, no estado do Rio de Janeiro, motivados por Beatrice Bemis, uma norte-americana, mãe de uma criança com Síndrome de Down. Em 1962, foi criada a Fundação Nacional da Associação de Pais e Amigos dos Excepcionais (SOUZA, 2016).

Em Minas Gerais, em 1956, na cidade de São Lourenço, foi implantada a primeira APAE do Estado e a segunda do Brasil. 
DEFESA DOS DIREITOS DAS PESSOAS COM DEFICIÊNCIA: A CONTRIBUIÇÃO DA ATUAÇÃO DO ASSISTENTE SOCIAL DA APAE DE TRÊS CORAÇÕES-MG, FUVAE E DO CONSELHO MUNICIPAL DE DIREITOS DAS PESSOAS COM DEFICIÊNCIA DE VARGINHA-MG

As APAEs são associações não governamentais que se enquadram juridicamente em entidades do Terceiro Setor. Para desempenhar todo esse trabalho e melhor atender às pessoas com deficiência e suas famílias, essas instituições contam com uma equipe técnica multidisciplinar, composta por psicólogos, neurologistas, psicopedagogos, fonoaudiólogos, terapeutas ocupacionais, assistentes sociais, dentre outros.

As APAEs atuam em aproximadamente 2.000 municípios brasileiros, favorecendo mais de 250.000 pessoas com deficiência, com foco nas áreas da Educação, Saúde e Assistência Social (FEDERAÇÃO NACIONAL DAS APAES, 2017).

Para superar desafios, de acordo com Barbosa (20 I7), em Minas Gerais as APAEs realizam projetos envolvendo as famílias dos usuários de seus serviços, como as escolas de pais ou famílias, que surgiram a partir da necessidade de fazer com que as famílias das pessoas com deficiência absorvessem conhecimentos e informações para a efetivação dos direitos de seus filhos.

nascimento de um filho com deficiência representa vários desafios, mobilizando as famílias sob os pontos de vista emocional, social, econômico, dentre outros, que se fragilizam diante das dificuldades, falta de apoio para superar o novo, o preconceito e adaptação à realidade (FUKUDA, CARVALHO e BUCHER-MALUSCHKE, 20I I).

Barbosa (2017) destaca a importância de as famílias terem certo saber sobre as reais limitações das pessoas com deficiência, fator essencial para que se organizem e ofereçam o apoio que seus filhos precisam para alcançar uma vida plena e participativa na própria família, na comunidade e em sociedade, para que não seja excluído socialmente.

Melo e Costa (20 I 6) relatam que o problema da exclusão social, em seu contexto histórico, se traduz como falta de acesso às oportunidades oferecidas pela sociedade aos seus membros, ou seja, um indivíduo é considerado socialmente excluído quando privado dos seus direitos sociais, civis ou econômicos.

Brasil vem criando políticas para garantia de direitos das pessoas com deficiência, como foi o caso da Política Nacional para a Integração da Pessoa Portadora de Deficiência (Lei n 7.853, de 1989), que já enfatizava ser dever do Estado ou do Poder Público prestar assistência aos cidadãos com algum tipo de deficiência, de forma a lhes garantir os direitos básicos (BRASIL, 1989).

$\bigcirc$ avanço mais recente sobre os Direitos e Inclusão das Pessoas com Deficiência foi a aprovação de seu Estatuto, a Lei de Inclusão da Pessoa com Deficiência, que reafirma esse dever de o Estado, a sociedade e a família garantirem os meios de acesso às pessoas com deficiência, em relação à vida, à saúde, à sexualidade, à paternidade e à maternidade, à alimentação, à habitação, à educação, à profissionalização, ao trabalho, à previdência social, à habilitação e à reabilitação, ao transporte, à acessibilidade, à cultura, ao desporto, ao turismo, ao lazer, à informação, à comunicação, aos avanços científicos e tecnológicos, à dignidade, ao respeito, à liberdade, à convivência 
familiar e comunitária, entre outros decorrentes da Constituição Federal, da Convenção sobre os Direitos das Pessoas com Deficiência e seu Protocolo Facultativo e das leis e de outras normas que garantam seu bem-estar pessoal, social e econômico (BRASI, 20|5)

\section{FUVAE, DA CIDADE DE VARGINHA, E APAE, DE TRÊS CORAÇÕES: CA- RACTERÍSTICAS E ATIVIDADES}

Com a idealização do casal Targino Hermógenes Nogueira Neto e Maria Aparecida Figueiredo Nogueira e outros casais convidados, em $1^{\circ}$ de fevereiro de |96।, fundaram juntos a Escola dos Excepcionais São Sebastião, em Varginha-MG, atualmente conhecida como Fundação Varginhense de Assistência aos Excepcionais (FUVAE).

Essa instituição se caracteriza como uma fundação beneficente, com atuação nas áreas de Assistência Social, Educação, Saúde, Prevenção, Trabalho, Profissionalização, Defesa e Garantia de Direitos, Esporte, Cultura, Lazer, Estudo, Pesquisa, Meio Ambiente e outros, sem fins lucrativos (FUVAE, 20I3).

De acordo com as informações cedidas por profissionais dessa Instituição, sua instalação se localiza em um prédio com espaço físico acessível e adaptado.

A estrutura possui vinte salas de aulas, sala de educação física, artes, laboratório de informática, gabinete médico, sala do assistente social e salas equipadas para atendimentos clínicos: fisioterapia, fonoaudiologia, psicologia e terapia ocupacional.

Também possui piscina térmica, estacionamento, marcenaria, salas de depósito, auditório, banheiros acessíveis, além do setor administrativo, com salas para a Direção Administrativa e Pedagógica, duas Secretarias, sala de espera e supervisão. Todos os pontos de acesso possuem elevador e rampas.

Tal instituição atende anualmente cerca de 1.400 pessoas, com idade entre 0 a 84 anos, dentre os quais estão crianças, jovens, adultos e idosos com deficiência intelectual, múltipla ou em processo de habilitação e reabilitação física.

A FUVAE conta com serviços especializados de saúde, educação, assistência social e atividades de lazer. A equipe técnica é composta por 88 funcionários, contratados via entidade, Prefeitura de Varginha, professores e supervisores pedagógicos designados pelo Estado e autônomos, dentre eles destacam-se: médico pediatra, nutricionista, terapeuta ocupacional, técnico(a) de enfermagem, fisioterapeuta, fonoaudiólogo(a), psicólogo(a), neurologista, diretor(a) e supervisor(a) pedagógico, secretários(as), porteiro, assistentes sociais, auxiliar de serviços gerais, entre outros.

Em relação aos recursos financeiros para custear os serviços e manter a instituição, a FUVAE recebe repasses do Conselho Municipal de Defesa dos Direitos da Criança e do Adolescente (COMDEDICA), de Varginha, por meio do Fundo da Infância e do Adolescente (FIA), Subvenção do Fundo Nacional de Assistência Social (FNAS), convênio com a Prefeitura local, parcerias e doações de empresas da cidade. 
DEFESA DOS DIREITOS DAS PESSOAS COM DEFICIÊNCIA: A CONTRIBUIÇÃO DA ATUAÇÃO DO ASSISTENTE SOCIAL DA APAE DE TRÊS CORAÇÕES-MG, FUVAE E DO CONSELHO MUNICIPAL DE DIREITOS DAS PESSOAS COM DEFICIÊNCIA DE VARGINHA-MG

Onze anos depois da criação da FUVAE, de Varginha, em março de 1972, por iniciativa do Rotary Clube, foi fundada a Associação de Pais e Amigos dos Excepcionais (APAE) no município de Três Corações. Tal instituição atende cerca de 250 pessoas, dentre as quais estão crianças, jovens e adultos com deficiência intelectual e múltipla.

De acordo com as informações cedidas pela secretária e coordenadora da APAE, a Instituição conta com serviços especializados de saúde, educação e assistência social. A equipe técnica é composta por 46 profissionais, dentre eles destacam-se psicopedagogos, psicólogos, terapeuta ocupacional, neurologista, fonoaudiólogos, enfermeiros e secretários, também conta com parcerias de médicos particulares da região e professores designados pelo Estado, bem assim, com a colaboração de alunos dos cursos de Psicologia, Enfermagem, Cosmetologia, Estética e Serviço Social da Unincor, para realização de estágios curriculares não remunerados.

O espaço físico da APAE, de Três Corações, é composto por dez salas clínicas, sala para atividades lúdicas, sala para atendimentos de pessoas autistas, uma brinquedoteca, doze salas de aula, salão de eventos, refeitório, secretaria e recepção.

Em relação aos recursos financeiros para custear os serviços e manter a instituição, a APAE recebe repasses da Prefeitura de Três Corações e do FIA, patrocínios de algumas empresas e comércios da cidade, e doações.

\section{PERFIL DAS FAMÍLIAS ENTREVISTADAS NA FUVAE E APAE}

A maioria das pessoas entrevistadas na FUVAE e na APAE são mães com idade que variam entre 29 e 60 anos, que dedicam seu tempo para cuidar dos filhos com deficiência.

A renda das famílias entrevistadas, tanto da FUVAE quanto da APAE, não ultrapassa dois salários mínimos, enquadra-se no perfil das famílias pesquisadas e descritas por Schmidt (20।3), Fukuda, Carvalho e Bucher-Maluschke (20II) e outros autores que indicam que o perfil da maioria das famílias assistidas pela rede APAE é de pessoas de classe econômica baixa, com renda entre 0 e 2 salários mínimos.Com a exceção de uma mãe entrevistada na APAE, que possui renda familiar com o valor equivalente a três salários mínimos.

De acordo com a entrevista realizada na FUVAE, das dez famílias entrevistadas, cinco delas têm renda proveniente do Benefício de Prestação Continuada (BPC), e uma família tem renda proveniente da aposentadoria por tempo de serviço. Das demais pessoas entrevistadas, a renda familiar é proveniente do exercício de trabalho remunerado de carteira assinada.

Já as entrevistas realizadas na APAE, de Três Corações, demonstram que das dez famílias entrevistadas apenas duas têm renda proveniente do BPC; uma delas recebe pensão alimentícia, uma recebe pensão por morte do ex-cônjuge, e apenas uma não recebe nenhum tipo de remuneração ou benefícios do Governo Federal, tendo como único meio de sustento a ajuda dos pais. Das demais pessoas entrevistadas, a 
renda familiar provém do exercício de trabalho remunerado, sendo uma delas autônoma e quatro trabalham com carteira assinada.

Observa-se que da maior parte das famílias entrevistadas que frequenta a APAE, a renda familiar não provém do Benefício da Lei Orçamentária Anual (LOA). Ao contrário das famílias entrevistadas na FUVAE, boa parte respondeu que a renda familiar provém do Benefício de Prestação Continuada (BP-C). Infere-se que as famílias entrevistadas da APAE, de Três Corações, possuem renda maior do que a das famílias entrevistadas na FUVAE, de Varginha.

Constatou-se também, nas entrevistas que o tempo de frequência das pessoas com deficiência e seus familiares na FUVAE é maior do que o das pessoas com deficiência e seus familiares na APAE. Os dados dos entrevistados apontam que na FUVAE têm seis famílias que frequentam os serviços da instituição há mais de cinco anos. Já na APAE, apenas três famílias entrevistadas frequentam a instituição há mais de cinco anos.

Esses dados tendem a apontar que, segundo Fukuda, Carvalho e Bucher-Maluschke (20l I), as organizações ou escolas especiais Apaeanas, mesmo em tempo de intensa defesa da inclusão escolar no País ainda constituem espaços acessíveis, abertos, disponíveis e de confiança da população para atender e acompanhar as pessoas com deficiência.

Nessa perspectiva, verificou-se que três pessoas com deficiência fazem atendimento na FUVAE (utilizam o projeto educacional pedagógico, o Atendimento Educacional Especializado (AEE), o qual reforça os aprendizados escolares) e estudam em escola da rede de ensino regular no município. Quanto à APAE, de Três Corações, esta tem um número de cinco pessoas que fazem o uso do atendimento educacional especializado para o reforço do aprendizado escolar.

Este atendimento é um projeto pedagógico inserido nas APAEs e visa assessorar e orientar a rede regular de ensino dos alunos que dele participam, contribuindo, assim, com o processo do ensino-aprendizagem e apoiando os profissionais da escola regular, como forma de garantir aos educandos, atendimentos mais adequados às suas necessidades (MELO e COSTA, 20 16, p. 6).

Pode-se notar que a questão da inclusão social no Brasil está se concretizando aos poucos, mas, como se sabe, a sociedade brasileira não é inclusiva. A inclusão social vem sendo efetivada em alguns setores sociais, como educação, lazer e transporte. A efetivação desse processo culminaria com a construção da "sociedade inclusiva": "Quanto mais sistemas comuns da sociedade adotarem a inclusão, mais cedo se completará a construção de uma verdadeira sociedade para todos - a sociedade inclusiva" (SASSAKI, 1999, p. 42).

Todavia, cabe destacar que autores como Marx e Mészáros, e seus seguidores, problematizam a dicotomia e dialética do termo inclusão/exclusão. Ressaltam que a exclusão e a inclusão social estão relacionadas ao sistema capitalista que tem viés excludente. Diante desse contexto, Pereira (2008) diz que as práticas inclusivas feitas pelo sistema capitalista somam-se como corretivos marginais, 
DEFESA DOS DIREITOS DAS PESSOAS COM DEFICIÊNCIA: A CONTRIBUIÇÃO DA ATUAÇÃO DO ASSISTENTE SOCIAL DA APAE DE TRÊS CORAÇÕES-MG, FUVAE E DO CONSELHO MUNICIPAL DE DIREITOS DAS PESSOAS COM DEFICIÊNCIA DE VARGINHA-MG

As reivindicações e as ações em torno de problemas sociais são previstas pelo sistema; ele permite tais atitudes como forma de correção dos seus defeitos, o que não significa que serão concretamente, corrigidos; isso Mészáros chama de corretivos marginais por não abalar as estruturas orgânicas do sistema capitalista e fazer com que se instale outra possibilidade de produção da existência humana (PEREIRA, 2008, p. 196).

$\bigcirc$ respeito à diversidade humana é passo para construirmos uma sociedade inclusiva, e a informação é fundamental para vencer as barreiras do preconceito e da discriminação, promovendo o respeito à diversidade.

Nesse sentido, segundo as informações retiradas nas entrevistas com as famílias na APAE, dos dez pais entrevistados apenas uma mãe relatou que percebe o preconceito das pessoas em relação ao seu filho autista, e essa situação a deixa triste. Outra mãe relatou que sua filha ainda não sofreu nenhum tipo de preconceito, mas ela teme futuramente passar por essa situação.

Quanto à FUVAE, das dez famílias entrevistadas, quatro responsáveis disseram que seus filhos não sofrem preconceito, e seis disseram que sentem que as pessoas ainda têm preconceito em relação às pessoas com deficiência, surge até mesmo entre os próprios familiares, e que uma das causas do preconceito é a falta de informação ou instrução.

Diante desse contexto, salienta-se a importância de as famílias terem conhecimento e se informarem sobre os direitos dos seus filhos e se posicionarem perante a sociedade, exigindo condições de acesso às oportunidades, acesso aos seus direitos, e a construção de uma sociedade inclusiva e igualitária.

Assim, tratando-se de informação e reconhecimento dos direitos da pessoa com deficiência, a FUVAE e a APAE têm importante papel para a inclusão na busca pelo reconhecimento dos direitos dessas pessoas.

\section{IMPACTO DA ATUAÇÃO DO(A) ASSISTENTE SOCIAL NA VIDA DOS USUÁRIOS E FAMILIARES DA FUVAE E DA APAE}

Nos tempos atuais, o Serviço Social apresenta uma feição acadêmico-profissional e social renovada, voltada para a defesa do trabalho e dos trabalhadores, compromissado com a democracia, liberdade, igualdade e justiça social, lutando pela afirmação dos direitos humanos (IAMAMOTO, 2009).

A profissão vem ganhando seu espaço nos diversos campos de atuação, como em instituições públicas e privadas, Organizações Não Governamentais (ONGs), no Terceiro Setor, na luta intransigente pelos direitos humanos, democratização e acesso aos serviços sociais.

Costa (2005) afirma que uma das atribuições específicas do assistente social no Terceiro Setor consiste em identificar, continuamente, necessidades individuais e 
coletivas apresentadas pelos segmentos que integram a instituição, na perspectiva do atendimento social e da garantia de seus direitos, implantando e administrando benefícios sociais. Dessa forma, o profissional de Serviço Social pode intervir na vida dos usuários e na de seus familiares, orientar e multiplicar as informações, fazer encaminhamentos dos assistidos aos recursos da sociedade e utilizar a rede de serviços socioassistenciais.

O profissional do Serviço Social que atua na FUVAE, de Varginha-MG, e na APAE, de Três Corações-MG, pode contribuir com a efetivação dos direitos das pessoas com deficiência e de suas famílias.

Na FUVAE, este setor é composto por duas assistentes sociais, que trabalham de forma articulada com outros setores dentro e fora desta Instituição. $\bigcirc$ setor de Serviço Social na FUVAE é responsável pelos acompanhamentos das famílias e dos usuários, objetivando a garantia dos direitos, convívio social e comunitário, participação e autonomia das pessoas com deficiência e de suas famílias.

As assistentes sociais da FUVAE destacam que atuam por meio de acolhida e escuta qualificada, acompanhamento especializado, articulação em rede e registro das informações.

Ressaltam que suas principais ações e atividades neste setor são: promover ações de acesso às informações, a garantia e defesa dos direitos,

[...] realizando através do acompanhamento social aos usuários e famílias, a escuta qualificada, visitas domiciliares e hospitalares, encaminhamentos, atividades de promoção e prevenção da saúde, prevenção e mediação em casos de evasão ou infrequência escolar, orientaç̃oes aos cuidados pessoais de higiene, organização do lar, manutenção da qualidade de vida e atividades diárias (Fala das Assistentes Sociais entrevistadas na FUVAE).

Ao observar fala em relação às atividades do assistente social em seu local de trabalho na FUVAE, nota-se ter sido mencionado "cuidados pessoais com higiene e organização do lar", tais práticas tendem à ideia de ajustamento dos indivíduos, realizadas nos anos iniciais da profissão.

[...] pressupunha-se os profissionais formados nas recémfundadas Escolas de Serviço Social (a partir de 1936) fossem atuar na mudança de comportamento das famílias e pessoas, para que melhorassem seus comportamentos e suas condições quanto à higiene, à moral e à sua inserção na ordem social (FALEIROS, 1997, p. 13).

Esses resultados tendem a apontar práticas do início da profissão, período em que o Serviço Social apresentava caráter conservador e visava ao ajustamento dos sujeitos à vida comunitária. 
DEFESA DOS DIREITOS DAS PESSOAS COM DEFICIÊNCIA: A CONTRIBUIÇÃO DA ATUAÇÃO DO ASSISTENTE SOCIAL DA APAE DE TRÊS CORAÇÕES-MG, FUVAE E DO CONSELHO MUNICIPAL DE DIREITOS DAS PESSOAS COM DEFICIÊNCIA DE VARGINHA-MG

A partir do Movimento de Reconceituação², a profissão vem ganhando novo viés, com o intuito de romper com as práticas tradicionais e conservadoras, tornando-se uma profissão com olhar crítico para a realidade (VIANA, CARNEIRO e GONÇALVES, 20I5).

Contudo, as pessoas atualmente têm a compreensão da importância do trabalho realizado pelo assistente social; a pesquisa com as famílias mostraram que elas estão cada vez mais procurando este assistente para obter orientações a respeito dos direitos e serviços ofertados pela Instituição.

As famílias que frequentam a FUVAE por um período maior estão vendo o assistente social como um mediador para o acesso aos direitos, e percebem a diferença de como este profissional atuava no passado e como atua no presente.

De acordo com a pesquisa realizada na Instituição, pode-se notar que a atuação profissional do assistente social reflete na vida dos usuários, acarretando mudanças significativas na vida das pessoas com deficiência e na de suas famílias.

Neste contexto, a fala de Vasconcelos (2002) situa que no papel do assistente social está o processo de socialização da informação como mecanismo de prática profissional, que deve conhecer a realidade do seu campo de atuação, compreender o contexto no qual se insere.

Os resultados apontaram que todas as famílias entrevistadas relatam mudanças na vida dos filhos e na dos familiares. Percebeu-se, pelos relatos das famílias, a importância da FUVAE e a atuação do assistente social, diante da viabilização de direitos.

Uma das principais orientações e viabilização de direitos se referem a: concessão de benefícios, como o Benefício de Prestação Continuada (BPC), bolsa família, gratuidade no transporte, tarifa social, isenção de impostos na aquisição de veículos, atendimentos prioritários e preferenciais, cultura, lazer, esporte, educação em escola de rede pública, benefícios eventuais, para aqueles que necessitam. Também fornecem orientações e encaminhamentos para a rede do município, ao acesso a outros benefícios, como medicamentos gratuitos, órteses e próteses, programa habitacional do Governo Federal Minha Casa Minha Vida.

Nesse sentido, pode-se destacar que o assistente social tem um importante papel para o reconhecimento e a busca pelos direitos das pessoas com deficiência.

Dessa forma, as dez famílias entrevistadas relataram que desconhecem as leis que amparam as pessoas com deficiência, e que aos poucos, e com a intervenção profissional do assistente social, estão tendo conhecimento dessas leis. As assistentes sociais da FUVAE consideram o seu trabalho profissional importante para

2 O Movimento de Reconceituação é um importante momento do Serviço Social, pois é partir daí que surge outra visão acerca da prática profissional, voltada a uma análise crítica da realidade social, buscando assim um melhor desempenho no agir profissional ao atender às demandas da questão social, pautado em bases teórico-metodológicas que buscam superar as práticas tradicionais do Serviço Social (VIANA, CARNEIRO e GONÇALVES, 20 I 5, p. I). 
esta instituição, porque contribui para com o desenvolvimento das pessoas com deficiência.

Todavia, o reconhecimento da profissão não é algo simples, no contexto profissional, as assistentes sociais da FUVAE relatam que a profissão implica alguns desafios diários, como tempo para conciliar os atendimentos, intervenções, acompanhamento familiar e burocracias do serviço; conscientização de algumas famílias e demais profissionais da instituição sobre a Política de Assistência Social; o verdadeiro papel do assistente social no atendimento e acompanhamento aos usuários e famílias; acompanhamento às famílias que sofrem mudanças a todo o tempo, com demandas de diversas ordens que chegam ao serviço Social diariamente.

lamamoto (2009) salienta que um dos desafios a serem enfrentados é o de que os assistentes sociais precisam redescobrir, a cada dia, alternativas e possibilidades para o trabalho profissional no cenário atual, traçando horizontes para que possam formular propostas que façam frente à questão social e sejam solidários como modo de vida daqueles que a vivenciam, não só como vítimas, mas como sujeitos que lutam pela preservação e conquista da sua vida, da sua humanidade.

Assim, por mais que haja desafios para a atuação dos assistentes sociais na FUVAE, há varias contribuições sociais do trabalho desenvolvido na vida das famílias assistidas nesta Instituição, como o desenvolvimento social efetivo do usuário e da família, garantia dos direitos, fortalecimento das relações família- FUVAE-comunidade, promoção da autonomia, recuperação da autoestima, fortalecimento dos vínculos familiares e comunitários, integração e participação da pessoa com deficiência na sociedade, contribuição com a inclusão e equidade dos usuários, ampliando o acesso aos bens e serviços socioassistencias básicos e especiais, auxílio à equipe pedagógica e clínica no esclarecimento de situações socioeconômicas que estejam interferindo na aprendizagem e desenvolvimento do usuário.

Quanto às pesquisas realizadas na APAE, da cidade de Três Corações, não foi possível entrevistar a assistente social, pois fora desligada da Instituição havia dois dias. A entrevistada foi a secretária coordenadora que está vinculada à APAE desde a sua fundação. Ela disse que as atribuições da assistente social são as de desenvolver um trabalho com as famílias; o profissional é direcionado a atender às famílias em todo o seu contexto e situações, e considera o Serviço Social fundamental para a APAE, caracterizando o trabalho do assistente social como a porta de entrada das famílias para a instituição, um espaço onde sempre há muita coisa para ser trabalhada. Devido às situações e dificuldades financeiras da APAE, estão com dificuldades de contratar um profissional que abrace a causa das pessoas com deficiência.

Segundo Oliveira (20।2), a atuação do assistente social está representada por alguns princípios de atendimento, quais sejam, as origens das emoções e atitudes. Deve-se desencadear um processo ação/reflexão com as famílias a partir dos problemas apresentados, criando percepções sobre as causas, condição, meios de encaminhamentos da realidade apresentada, visando sempre ao desenvolvimento de suas próprias potencialidades. 
DEFESA DOS DIREITOS DAS PESSOAS COM DEFICIÊNCIA: A CONTRIBUIÇÃO DA ATUAÇÃO DO ASSISTENTE SOCIAL DA APAE DE TRÊS CORAÇÕES-MG, FUVAE E DO CONSELHO MUNICIPAL DE DIREITOS DAS PESSOAS COM DEFICIÊNCIA DE VARGINHA-MG

Desse modo, as famílias entrevistadas na APAE falaram sobre as contribuições do assistente social para a sua vida pessoal e familiar, destacando a importância das orientações desse profissional para os pais ou responsáveis, em relação aos direitos das pessoas com deficiência.

É nítido constatar a falta que a atuação do assistente social faz para a Instituição, pois muitas pessoas que frequentam a APAE, de Três Corações, são famílias com pouco acesso às informações, e o pouco conhecimento dos direitos dos filhos com deficiência que têm foram repassados principalmente pelo setor de Serviço Social.

A Secretaria Coordenadora da APAE ressalta que o assistente social na Instituição contribui para a organização da vida das famílias e às conquistas dos direitos das pessoas com deficiência. As próprias famílias entrevistadas também reconhecem as contribuições do trabalho do assistente social na orientação em relação aos direitos, às leis que amparam as pessoas com deficiência, e citaram a falta que este profissional faz à Instituição.

Com essa pesquisa, foi possível verificar a importância da atuação do assistente social na Entidade de Amparo a pessoas com deficiência, suas possibilidades de intervenção e contribuições para a vida das famílias. Ser assistente social é um desafio para a categoria profissional, mas com inovação, conhecimento e dedicação podem fazer a diferença na vida de usuários.

Outras importantes Organizações destinadas a pessoas com deficiência são os Conselhos, que também possuem um papel na defesa e luta pelos direitos sociais, sendo assim, como exemplo, a seguir são descritas as contribuições do Conselho de Varginha na vida das pessoas com deficiência.

\section{CONSELHO MUNICIPAL DE DEFESA DOS DIREITOS DA PESSOA COM DEFICIÊNCIA, DE VARGINHA, CODEVA}

Segundo Alves (20|4), no Brasil, a prática de participação nos Conselhos não é recente, os anos de 1970 e 1980 foram marcados pela experiência de conselhos comunitários, populares e setoriais. Em 1988, com a Constituição Federal e suas leis orgânicas, esses espaços foram regulamentados, e a partir dos anos 1990 tornaram-se órgãos permanentes e de composição paritária entre representantes do poder público e da sociedade civil.

A importância dos Conselhos está no seu papel de fortalecimento da participação democrática da população, na formulação e implementação dessas políticas públicas (BRASIL, 20 18). A prática dos Conselhos possibilita o controle social, qual seja, instrumento de efetivação da participação e controle popular no processo de gestão política, administrativa, financeira e técnico-operativa das políticas públicas (SILVA, 2007).

Atuam nas esferas municipais, estaduais e nacional, em diversas áreas e segmentos, como Saúde, Educação, Assistência Social, do Idoso, da Mulher, das Pessoas com Deficiência e outros. 
Em junho de 1999, com o Decreto n 3.076, foi criado o Conselho Nacional da Pessoa com Deficiência, com a principal atribuição de garantir a implementação da Política Nacional de Integração da Pessoa com Deficiência (BRASIL, 1999).

Os objetivos dos Conselhos estaduais e municipais voltados para pessoas com deficiência são: propor, acompanhar e avaliar as políticas relativas aos direitos sociais, com capacidade de interiorização das ações, dispondo de autonomia administrativa e financeira (BRASIL, 2007).

O Conselho deve ser constituído, paritariamente, por representantes de instituições governamentais e da sociedade civil, observando-se, entre outros requisitos, a representatividade e a efetiva atuação estadual e municipal, relativamente à defesa dos direitos da pessoa com deficiência. Quanto ao período de mandato, cada estado ou município tem independência para defini-lo (BRASIL, 2007).

Os conselheiros possuem a função de participar e votar nas reuniões, relatar as matérias em estudo, promover e apoiar o intercâmbio e a articulação entre instituições governamentais e privadas na área de atuação do Conselho. Também recebem e encaminham as demandas da população com deficiência (BRASIL, 20 I 0).

Além da atuação política, os conselheiros deverão dar conhecimento aos seus representados, relatando matérias e atuando diretamente na rede de articulação entre seus pares. Cabe, ainda, atuar na sensibilização da sociedade em geral acerca da defesa dos direitos das pessoas com deficiência (BRASIL, 20 I2).

Conforme a Secretaria Especial dos Direitos da Pessoa com Deficiência (BRASIL, 20 I 8), no Brasil há 27 Conselhos Estaduais dos Direitos da Pessoa com Deficiência e 589 Conselhos Municipais, dentre estes, em Minas Gerais, 26 Conselhos Municipais atuantes distribuídos pelo Estado.

Em específico, o Conselho Municipal de Defesa dos Direitos da Pessoa com Deficiência, de Varginha (CODEVA), foi criado pela Lei no 4.559, de 2006. É um órgão de administração pública, que faz parte da Secretaria de Governo da Prefeitura de Varginha, representado pela sociedade civil e pelo poder governamental, cuja função é regular, controlar, fiscalizar e defender as políticas de atendimento às pessoas com deficiência no município.

O CODEVA trabalha pela construção de uma sociedade mais igualitária e acolhedora, em que todos tenham acesso à saúde, ao lazer, à cultura, à arte, ao turismo, e sejam atendidos em todas as necessidades inerentes ao ser humano, norteado por princípios, como a segurança, inclusão social e igualdade, eliminação de barreiras e superação de preconceitos.

Atualmente, o espaço físico do CODEVA é emprestado pela Secretaria de Saúde do município de Varginha. A sede conta com instalações de duas salas, recepção e banheiros adaptados e acessíveis. Mantém suas ações com recursos obtidos por meio de patrocínios de empresas e convênio com a Prefeitura local.

Com o compromisso de desenvolver ações voltadas às pessoas com deficiência, no município de Varginha, o CODEVA, ao longo dos seus dez anos, já realizou 
DEFESA DOS DIREITOS DAS PESSOAS COM DEFICIÊNCIA: A CONTRIBUIÇÃO DA ATUAÇÃO DO ASSISTENTE SOCIAL DA APAE DE TRÊS CORAÇÕES-MG, FUVAE E DO CONSELHO MUNICIPAL DE DIREITOS DAS PESSOAS COM DEFICIÊNCIA DE VARGINHA-MG

conquistas atitudinais, como campanhas educativas, seminários, colônia de férias acessível, palestras, capacitação para conselheiros; conquistas arquitetônicas, como adaptação da Prefeitura, Câmara dos Vereadores e Theatro Capitólio, transporte coletivo adaptado, vagas de estacionamento para veículos; conquistas comunicacionais com cursos de Libras e Braille; conquistas de ajudas técnicas, como sala multimídia adaptada, aquisição de carteiras escolares, criação da Coordenadoria de Mobilidade Urbana e Acessibilidade, que desencadeou o programa Transporte Porta a Porta Adaptado.

De acordo o senso do IBGE (20 I0), 27.700 pessoas na cidade de Varginha/MG apresentam algum tipo de deficiência, esta parcela da população necessita de ações pontuais para que sejam respeitadas e ganhem visibilidade, e que o ciclo da exclusão social seja quebrado.

Haja vista a quantidade de pessoas com deficiência no município de Varginha, o CODEVA tem como objetivos desafiadores combater toda a forma de preconceito e discriminação; fortalecer o conceito de acessibilidade e inclusão da pessoa com deficiência na sociedade; promover eventos que oportunizem reflexões, discussões e avanços no processo de inclusão da pessoa com deficiência no município, entre outros.

Vilela (2005) situa que a formação dos Conselhos é uma maneira de a sociedade organizada interagir com o Estado na definição de prioridades e na elaboração de políticas públicas, federal, estadual e municipal, de forma democratizada.

Nesse sentido, o CODEVA se define como um Conselho Municipal voltado para a defesa dos direitos das pessoas com deficiência, paritário, composto por dezesseis instituições governamentais e dezesseis instituições da sociedade civil, e, por ser um órgão municipal, todos os representantes são indicados pelas instituições da cidade de Varginha. Possui caráter consultivo, deliberativo, normativo e fiscalizador.

De acordo com o CODEVA (20 I 8), seu trabalho é realizado por meio de campanhas, informando sobre os direitos assegurados às pessoas com deficiência; desenvolvendo ações que visem à eliminação de barreiras arquitetônicas para a plena participação dessas pessoas; encaminhamento de currículos ao mercado de trabalho; acompanhamento de políticas públicas voltadas a estas pessoas; assessoria às pessoas com deficiência em defesa dos seus direitos.

Segundo o relato, os trabalhos se justificam porque as pessoas com deficiência necessitam de ações pontuais que sejam respeitadas, que ganhem visibilidade e quebrem o ciclo da exclusão. Seu maior desafio atualmente é a construção de um centro de referência para as pessoas com deficiência. A cada ano, o CODEVA cria um tema para suas ações; em 2018, o projeto trouxe como temática Inclusão para todos.

Conforme as informações cedidas pelos participantes da entrevista, o tempo de atuação e participação das ações dos conselheiros e colaboradores no CODEVA varia entre um e oito anos. 
A maioria dos entrevistados participa do CODEVA, e não de outros Conselhos. Estes destacam a importância dos Conselhos de direitos e sua atuação nas cidades.

Os conselhos exercem importante papel em Varginha, pois são canais de participação democrática da população na formulação e implementação de politicas públicas, o que permite vivenciarmos uma sociedade mais justa e igualitária (Fala do Conselheiro/colaborador entrevistado).

Um conselheiro aponta que a atuação do CODEVA é importante para o projeto de inclusão das pessoas com deficiência na sociedade, com respeito e qualidade de vida.

Outro conselheiro aponta que é referência para as cidades vizinhas, destacando-se, na opinião deste, como um dos melhores Conselhos do Brasil - órgão de instrumento público atuante no município, que realmente visa à inclusão para todos.

Um colaborador participante das ações do Conselho diz que

Os conselhos são importantes para promover os recursos, informaç̧ões, direitos e obrigações. Serve para interagir com a sociedade no âmbito municipal, estadual e federal (Fala Conselheiro/colaborador entrevistado).

Quanto às contribuições deste Conselho para a vida pessoal e atuação profissional dos conselheiros e colaboradores, um dos colaboradores que tem deficiência destaca que o Conselho contribui para aproximar as pessoas com deficiência umas das outras, e o CODEVA age como apoio para elas.

Em entrevista, foi verificado que o CODEVA contribui para que os direitos das pessoas com deficiência sejam respeitados e para que estas participem da vida em sociedade em vários aspectos:

- CODEVA contribui muito em minha vida pessoal e profissional, pois é de suma importância conhecer os direitos d pessoa com deficiência e contribui para que estes direitos sejam assegurados par a efetiva participação das pessoas com deficiência nos vários aspectos da sociedade: cultural, econômico, social e politico (Fala do Conselheiro/ colaborador entrevistado)

Conselheira relata que o CODEVA contribui para o crescimento pessoal e profissional, as pessoas passam a ter conhecimento do que acontece ao seu redor, mudando a forma de olhar para a sociedade, passando a tratar as pessoas deficientes com igualdade, enxergando nelas as suas potencialidades.

De acordo com o CONADE (BRASIL, 20I0), uma das políticas de atendimento à pessoa com deficiência no âmbito municipal se dá por meio de programas e serviços sociais básicos de educação, saúde, recreação, esporte, cultura, lazer, profissionalização, dentre outros. Nesse sentido, um dos colaboradores destaca que o 
DEFESA DOS DIREITOS DAS PESSOAS COM DEFICIÊNCIA: A CONTRIBUIÇÃO DA ATUAÇÃO DO ASSISTENTE SOCIAL DA APAE DE TRÊS CORAÇÕES-MG, FUVAE E DO CONSELHO MUNICIPAL DE DIREITOS DAS PESSOAS COM DEFICIÊNCIA DE VARGINHA-MG

CODEVA tem importante contribuição para o acesso das pessoas aos meios que a sociedade pode oferecer.

Nota-se pela pesquisa realizada com os conselheiros e colaboradores do CODEVA que este Conselho é um órgão importante para a representação da sociedade, pois leva conhecimento, viabiliza o acesso aos direitos para as pessoas e visa conquistar uma sociedade justa com igualdade de condições.

\section{CONSIDERAÇÕES FINAIS}

Este artigo tratou sobre a atuação da APAE, FUVAE e CODEVA na defesa e viabilização dos Direitos das Pessoas com Deficiência sob a ótica de assistentes sociais, e de familiares da APAE, FUVAE e conselheiros, colaboradores do CODEVA.

Cabe destacar que mesmo sendo um campo importante para a atuação do Serviço Social, foram poucas bibliografias encontradas a respeito da atuação e das contribuições sociais do trabalho do assistente social nas APAEs, e também sobre a atuação dos Conselhos de direitos das pessoas com deficiência nos municípios.

Verificou-se que a FUVAE e APAE são instituições sem fins lucrativos que trabalham com a oferta de serviços que visam à promoção e reabilitação da pessoa com deficiência intelectual e múltipla, e sua inclusão à vida comunitária, por meio dos serviços e programas, com vista a reduzir as incapacidades, desenvolver as potencialidades e habilidades para o trabalho e promover a inclusão social, a independência, a segurança, o acesso aos direitos e a participação na sociedade.

Com ênfase na FUVAE, de Varginha, e na APAE, de Três Corações, constatou-se que o perfil das famílias entrevistadas, assistidas por ambas as instituições, são famílias cuja renda mensal não ultrapassa o valor de dois salários mínimos, sendo consideradas famílias de baixo nível socioeconômico e possuem acesso às informações devido, principalmente, à intervenção de assistente social.

Na FUVAE, o trabalho das assistentes sociais contribui para o desenvolvimento social efetivo do usuário e da família, na garantia dos direitos, fortalecimento das relações família-FUVAE-comunidade, promoção da autonomia dos sujeitos, recuperação da autoestima, inclusão e equidade dos usuários, ampliando o acesso aos bens e serviços socioassistenciais básicos e especiais.

Dessa maneira, o assistente social passa a desenvolver um importante papel para o reconhecimento e a busca pelos direitos das pessoas com deficiência, o que reflete diretamente na vida dessas pessoas e de suas famílias, podendo contribuir para a emancipação.

Quanto às pesquisas realizadas na APAE, da cidade de Três Corações, verificou-se que os serviços prestados pelo assistente social são indispensáveis, pois o este é responsável pelas orientações, acolhimento, escuta qualificada, desenvolvimento dos projetos, encaminhamento e direcionamento das famílias para a conquista e acesso aos direitos.

Ressalta-se que, do ponto de vista das famílias, o assistente social não é apenas um profissional que presta seus serviços à Instituição, ele é reconhecido como um profis- 
sional amigo, acolhedor, sempre disposto a ouvir e aconselhar as pessoas, tornando-se referência para as famílias na busca da efetivação dos direitos das pessoas com deficiência.

Percebe-se que atualmente as pessoas têm a compreensão da importância do trabalho realizado pelo assistente social, pois a pesquisa com as famílias mostrou que aquelas estão cada vez mais procurando este profissional para ter orientações a respeito dos direitos e serviços ofertados pela Instituição.

Quanto à atuação do Conselho, no município de Varginha, a pesquisa realizada com os conselheiros do CODEVA possibilitou detectar a importância de ser ativo para a comunidade no processo de descentralização e democratização das políticas sociais, na defesa e ampliação dos direitos das pessoas com deficiência.

\section{REFERÊNCIAS}

ALVES, C. C. Valores Pessoais na atuação em conselhos municipais: o caso dos CMAS de Minas Gerais. 2014. I04f. Dissertação (Mestrado em Gestão Pública e Sociedade) Universidade Federal de Alfenas, Campus Varginha-MG, 2014.

BARBOSA, E. Escola de Família: Metodologia de trabalho social com famílias da rede mineira das Apaes. Minas Gerais: Federação das Apaes do Estado Minas Gerais-FEAPAES/MG, 2017. Disponível em: <http://uniapaemg.org.br/wp-content/ uploads/20 17/10/cartilha_escola_familia_I I pt.pdf >. Acesso em: 29 mar. 2018.

BRASIL. Decreto n 3076 de $1^{\circ}$ de junho de 1999. Cria, no âmbito do Ministério da Justiça, o Conselho Nacional dos Direitos da Pessoa Portadora de DeficiênciaCONADE, e dá outras providências. Diário Oficial [da] República Federativa do Brasil. Brasília, DF, 2 jul. 1999.

BRASIL. Lei n 7853, de 24 de outubro de 1989. Dispõe sobre o apoio às pessoas portadoras de deficiência, sua integração social, sobre a Coordenadoria Nacional para Integração da Pessoa Portadora de Deficiência - Corde, institui a tutela jurisdicional de interesses coletivos ou difusos dessas pessoas, disciplina a atuação do Ministério Público, define crimes, e dá outras providências. Diário Oficial [da] República Federativa do Brasil. Brasília, DF, 25 out. 1989. Disponível em: < http:// www.planalto.gov.br/ccivil_03/leis/L7853.htm>. Acesso em: 20 jul. 2018.

. Lei n 13.|46, de 6 de julho de 2015. Institui a Lei Brasileira de Inclusão da Pessoa com Deficiência (Estatuto da Pessoa com Deficiência). Diário Oficial [da] República Federativa do Brasil. Brasília, DF, 06 jul. 20I5. Disponível em: <http:// www.planalto.gov.br/ccivil_03/_ato20 I 5-20 I8/20 I5/lei// I I 46.htm>. Acesso em: 21 ago. 2017.

BRASIL. Conselho Nacional Dos Direitos Da Pessoa Com Deficiência- CONADE. Diretrizes para Criação de Conselhos Estaduais e Municipais dos Direitos da Pessoa com Deficiência. Brasília: Secretaria Especial dos Direitos Humanos; CONADE 2007. 
DEFESA DOS DIREITOS DAS PESSOAS COM DEFICIÊNCIA: A CONTRIBUIÇÃO DA ATUAÇÃO DO ASSISTENTE SOCIAL DA APAE DE TRÊS CORAÇÕES-MG, FUVAE E DO CONSELHO MUNICIPAL DE DIREITOS DAS PESSOAS COM DEFICIÊNCIA DE VARGINHA-MG

Conselho Nacional Dos Direitos Da Pessoa Com Deficiência- CONADE. Diretrizes para criação de Conselhos Estaduais e Municipais dos Direitos da Pessoa com Deficiência. Brasília, DF; Secretaria Especial dos Direitos Humanos, 2010.

Conselho Nacional Dos Direitos Da Pessoa Com Deficiência- CONADE. Diretrizes para criação de Conselhos Estaduais e Municipais dos Direitos da Pessoa com Deficiência. Brasília, DF; Secretaria Especial dos Direitos Humanos, 2012.

BRASIL. Secretaria Especial Dos Direitos Da Pessoa Com Deficiência. Conselhos no Brasil, 2018. Conselho Nacional dos Direitos das Pessoas com DeficiênciaCONADE, Brasilia: Secretaria Especial Dos Direitos Da Pessoa Com Deficiência; CONADE, 2018. Disponível em: <http://www.pessoacomdeficiencia.gov.br/app/ conade/conselhos-no-brasil>. Acesso em: 7 mai. 2018.

CONSELHO MUNICIPAL DE DEFESA DOS DIREITOS DA PESSOA COM DEFICIÊNCIA DE VARGINHA-CODEVA. Projeto XI Varginha Acessível. Varginha: WEspanha, 2018.

COSTA, S. F. O Serviço Social e o terceiro setor. Serviço Social em revista[online], Londrina, jan./jun. 2005, v.7, n. 2. Disponível em: < http://www.uel.br/revistas/ ssrevista/c_v7n2_selma.htm>. Acesso em: 12 out. 2017.

FALEIROS, V. P. Estratégias em Serviço Social. São Paulo: Cortez, 1997.

FEDERAÇÃO NACIONAL DAS APAES. História: Fenapaes, Rede APAE e sua história. Brasília, 20 17. Disponível em: < https://apaebrasil.org.br/page/2>. Acesso em: 23 ago. 2017.

FUKUDA, C. C.; CARVALHO, E. N. S.; BUCHER-MALUSCHKE, J. (Org.) A família no contexto da deficiência: estrutura e dinâmica. Brasília: Federação Nacional das Apaes, 201I. Disponível em: <https://apaebrasil.org.br/uploads/5155-a_familia_ no_contexto.pdf >. Acesso em: 02 abr. 2018.

FUNDAÇÃO VARGINHENSE DE ASSISTENCIA AOS EXCEPCIONAIS-FUVAE. FUVAE: Apae de Varginha.Varginha, Minas Gerais, 2013. Disponível em: http:// fuvaeapae.blogspot.com.br/. Acesso em: 31 mar. 2018.

IAMAMOTO, M. V. O Serviço Social na cena contemporânea. In: CONSELHO FEDERAL DE SERVIÇO SOCIAL. Serviço Social: Direitos Sociais e Competências Profissionais. CFESS, 2009, p. 0l-45. Disponível em: < file:///C:/Users/Perfil/ Downloads/LIVRO\%20COMPLETO\%20-\%20\%20CFESS\%20-\%20Servico\%20 Social\%20Direitos\%20Sociais\%20e\%20Competencias\%20Profissionais\%20\%20 -2009\%20(3).pdf>. Acesso em: 22 mai. 2018. 
INSTITUTO BRASILEIRO DE GEOGRAFIA E ESTATÍSTICA-IBGE. Censo demográfico 20 10: Características gerais da população e pessoas com deficiência. Rio de Janeiro: IBGE, 20 I0. Disponível em: <http://mww.ibge.gov.br/home>. Acesso em: 22 ago. 2017.

LANNA JÚNIOR, M. C. M. História do movimento político das pessoas com deficiência no Brasil. Brasília: Secretaria de direitos humanos, 2010.

MARQUES, E. S. História da Associação de Pais e Amigos dos Excepcionais (APAE) de Rolândia 1970-1980. Londrina. 20 I I. 57 f. Monografia (Graduação em Pedagogia) - Universidade Estadual de Londrina, Londrina, 20 I I. Disponível em: <http://www.uel.br/ceca/pedagogia/pages/arquivos/ELISANGELA\%20DA\%20 SILVA\%20MARQUES.pdf>. Acesso em: 31 out. 2017.

MELO, I. M.; COSTA, C. R. APAE: Um estudo sobre as formas de inclusão voltada para pessoas com deficiência. In: CONGRESSO NACIONAL DE EDUCAÇÃOCONEDU, 3, 2016, Natal. Anais...Natal: Cenários contemporâneos: a educação e suas multiplicidades, 2016, p. I-10. Disponível: <http://www. editorarealize.com.br/revistas/conedu/trabalhos/TRABALHO_EV056_MDI_SAI4 IDI0288_|70820|6002449.pdf>. Acesso em: 6 abr. 2018.

OLIVEIRA, C. M. A atuação do Assistente Social na Associação de Pais e Amigos dos Excepcionais. 2012. 62 f. Monografia (Graduação em Serviço Social) - Universidade Federal do Rio Grande do Norte, Natal, 20 I 2. Disponível em: <https://monografias. ufrn.br/jspui/bitstream/I 23456789/4209/I/Cla\%C3\%BAdiaMO_Monografia.pdf > . Acesso em: $1^{\circ}$ abr. 2018.

PEREIRA, A. Pode existir inclusão social de pessoas deficientes no mundo do trabalho e da educação capitalista?.Revista Educação Especial, Santa Maria. v. 21 , n. 32, p. 189-200, 2008. Disponível em: <https://periodicos.ufsm.br/educacaoespecial/ article/view/96>. Acesso em: 30 maio 2018

SASSAKI, R. K. Inclusão: Construindo uma sociedade para todos. Rio de Janeiro: WA, 1999.

SILVA, V. B. Dicionário de termos técnicos da Assistência Social. Secretaria Municipal Adjunta de Assistência Social. Belo Horizonte: ASCOM, 2007. Disponível em: < http:// mww.cedecacasarenascer.org/uploads_arquivos/ivros/I 705 175954000000 -dicionario _ de_termos_tecnicos_da_assistencia_social_2007.pdf >. Acesso em: 4 maio 2018.

SCHMIDT, P. Contribuições do projeto de intervenção de estágio supervisionado em Serviço Social na Associação de Pais e Amigos dos Excepcionais (APAE) de Panambi/RS. 2013. 78 f. Monografia (Curso do Serviço Social), Departamento de Ciências Jurídicas e Sociais)- Universidade Regional do Noroeste do Estado do Rio Grande do Sul-UNIJUÍ, 2013. Disponível em: < http://bibliodigital.unijui.edu. br:8080/xmlui/bitstream/handle/I 23456789/2 193/TCC\%20Priscila\%20Schmidt. pdf? sequence $=\mid>$. Acesso em: 10 abr. 2018. 
DEFESA DOS DIREITOS DAS PESSOAS COM DEFICIÊNCIA: A CONTRIBUIÇÃO DA ATUAÇÃO DO ASSISTENTE SOCIAL DA APAE DE TRÊS CORAÇÕES-MG, FUVAE E DO CONSELHO MUNICIPAL DE DIREITOS DAS PESSOAS COM DEFICIÊNCIA DE VARGINHA-MG

SOUZA, J. S. O Movimento Apaeano no Brasil, ações em benefício das pessoas com deficiência. Site Revista Campo e Cidade [online]. 2016, v. I05. Disponível em: $<$ http://www.campoecidade.com.br/category/edicao- I05-apae-de-itu-50-anos-dehistoria-amor-e-respeito/>. Acesso em: $1^{\circ}$ nov. 2017.

VASCONCELOS, E. M. Saúde Mental e Serviço Social: o desafio da subjetividade e da interdisciplinaridade. São Paulo: Cortez, 2002.

VIANA, B. B.; CARNEIRO, K. K. C.; GONCALVES, C. F. O Movimento de Reconceituação do Serviço Social e seu reflexo no exercício profissional na contemporaneidade. In: I SEMINÁRIO NACIONAL DE SERVIÇO SOCIAL, TRABALHO EPOLÍTICASSOCIAIS, I , 20 I 5, Florianópolis-SC. Anais... Florianópolis: UFSC, 2015, p. 1-8. Disponível em: <http://seminarioservicosocial20 17.ufsc.br/ files/2017/05/Eixo_2_139.pdf>. Acesso em: 30 maio 2018.

VILELA, M. D. de A. Legislação que disciplina os conselhos de politicas públicas. Site Câmara Legislativa de Brasília, 2005. Disponível em: < http://www2.camara. leg.br/a-camara/documentos-e-pesquisa/estudos-e-notastecnicas/areas-da-conle/ tema6/2005_740.pdf>. Acesso em: 27 mar. 2018.

Recebido em: 14/04/2019

Aprovado em: 05/06/2019 
